\title{
ANALYSIS OF THE UNITED STATES HOP MARKET
}

\author{
A Thesis \\ presented to \\ the Faculty of California Polytechnic State University, \\ San Luis Obispo
}

In Partial Fulfillment

of the Requirements for the Degree

Master of Science in Agribusiness

by

Michael Warren Dasso

June 2015 
(C) 2015

Michael Warren Dasso

ALL RIGHTS RESERVED 
TITLE:

AUTHOR:

DATE SUBMITTED:

COMMITTEE CHAIR:

COMMITTEE MEMBER:

COMMITTEE MEMBER:
Analysis of the United States Hop Market

Michael Warren Dasso

June 2015

Michael McCullough, Ph.D.

Professor of Agribusiness

Sean P. Hurley, Ph.D.

Professor of Agribusiness

Andrew Holtz, D.Eng.

Professor of BioResource \& Agricultural

Engineering 


\section{ABSTRACT \\ Analysis of the United States Hop Market \\ Michael Warren Dasso}

Hops are one of the four main ingredients used to produce beer. Many studies have been done to analyze the science behind growing and harvesting hops, creating hop hybrids, and how to brew beer with hops. However, there has been little research done revolving around the economic demand and supply model of the hop market. The objectives of this study are to create an econometric model of supply and demand of hops in the United States from 1981 to 2012 , and to identify important exogenous variables that explain the supply and demand of hops using the two-stage least squares (2SLS) method of analysis. Using the 2SLS method, the demand model yielded that the US beer production variable is significant at the 10 percent level. For every 1 percent change in US beer production, there will be a 6.25 percent change in quantity of hops demanded in the same direction. The supply model showed that US acreage is significant at the 1 percent level. For every 1 percent change in US acreage, there will be a 0.889 percent change in quantity of hops supplied in the same direction. The implications of this study are viewed in relation to both producers and consumers.

Keywords: hop, demand, supply, two-stage least squares, instrumental variable estimation. 


\section{ACKNOWLEDGMENTS}

I would like to thank all those who helped me and made this study possible. Firstly, I would like to thank my committee advisors, Professor Michael McCullough, Professor Sean Hurley, and Professor Andrew Holtz for guiding me through this process for you constant support and advice. This project has been a great learning experience to me. Secondly, I would like to thank all of the professors and staff here at Cal Poly that have helped me along my journey here at some point. You all have helped me to realize what great potential we all have, and how to reach that potential. Third and finally, I would like to thank my friends

and family for your constant love and support. And especially to my parents who have helped me throughout my entire academic career, and without whom I would not be who I am today. 
LIST OF TABLES ix

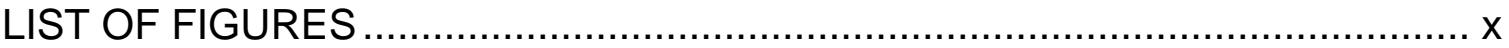

CHAPTER

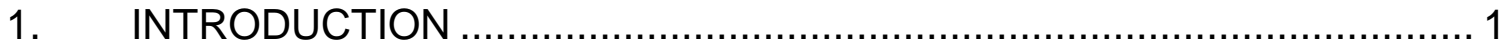

Problem Statement …............................................................... 4

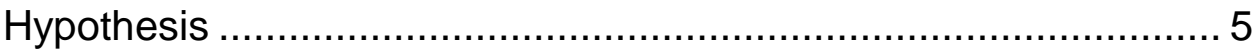

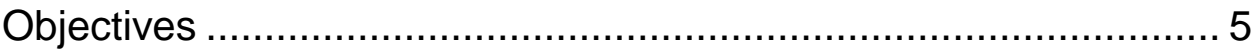

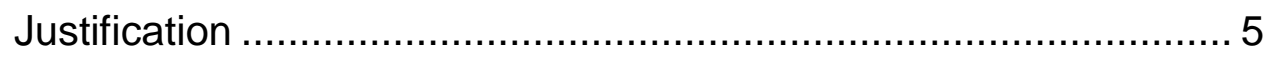

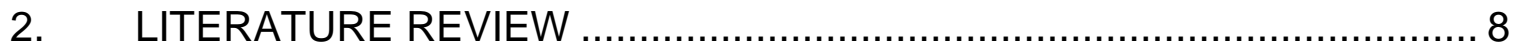

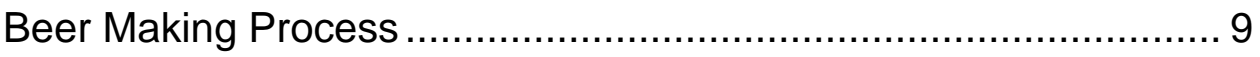

Hops

Foreign Studies on Hops ......................................................... 11

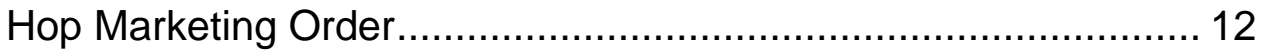

Other Agricultural Factors ….................................................... 15

Studies on Econometric Analysis ............................................. 16

Simultaneous Equation Systems..................................... 16

Instrumental Variables Estimation by Two-Stage

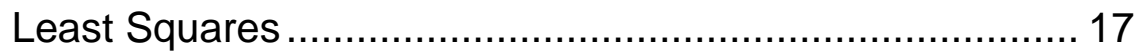




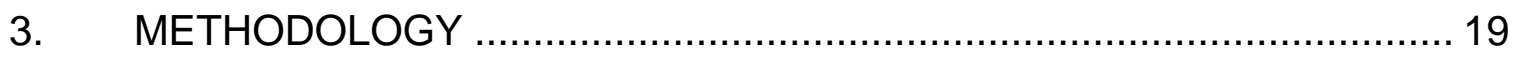

Procedures for Data Collection ............................................... 19

Procedures for Data Analysis.................................................... 26

Conditions for Identification ........................................... 27

Multicollinearity Test..................................................... 28

Instrumental Variables Estimation by Two-Stage Least

Squares and Autocorrelation Test .................................. 29

Simultaneous Equations...................................... 29

Instrumental Variables Estimation by Two-Stage

Least Squares .................................................. 30

First Stage ............................................... 30

Second Stage .......................................... 31

Autocorrelation Problem ................................ 32

Durbin-Watson Test..................................... 32

Endogeneity Test …................................................... 33

Assumptions and Limitations .................................................. 34

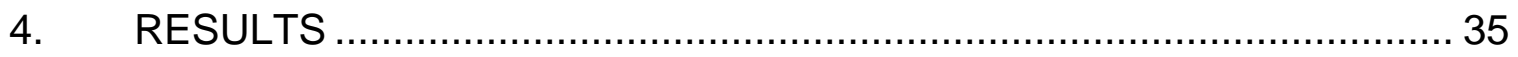

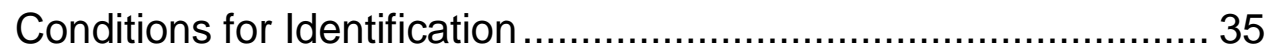

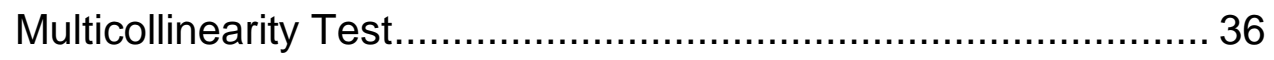

Instrumental Variables Estimation by Two-Stage Least Squares

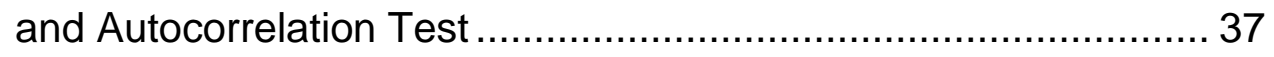

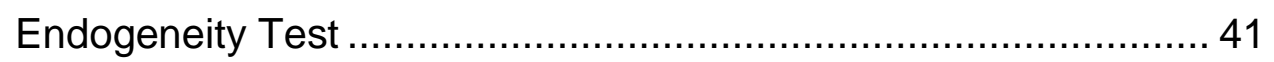

5. SUMMARY, CONCLUSIONS, AND RECOMMENDATIONS ................. 43 
Summary

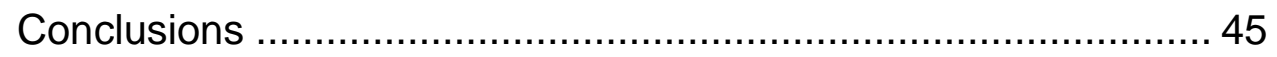

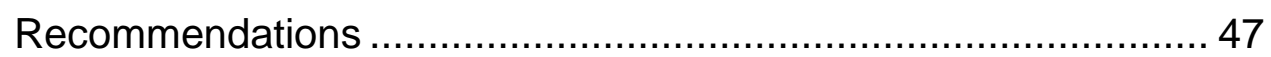

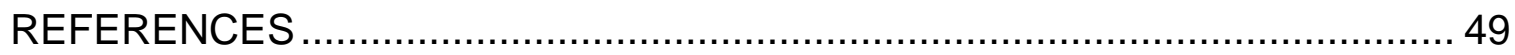

\section{APPENDICES}

1. Complete Data Set of Demand and Supply Model, 1981-2012 _......... 52 


\section{LIST OF TABLES}

Table

Page

1 Description of Data and Sources .................................................... 20

2 Descriptive Statistics of Variable Data.............................................. 22

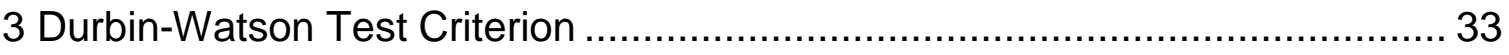

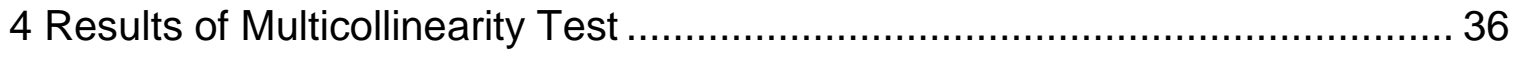

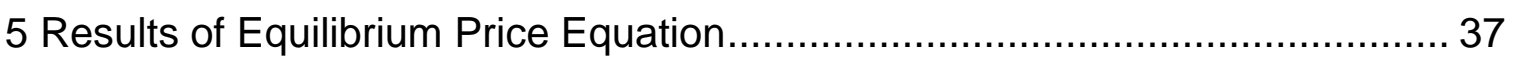

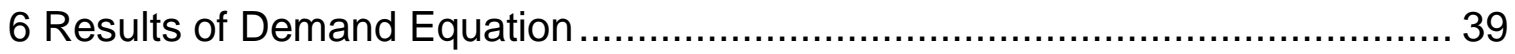

7 Results of Supply Equation............................................................ 40

8 Results of Endogeneity Test of Demand Equation ................................ 41

9 Results of Endogeneity Test of Supply Equation................................ 42 


\section{LIST OF FIGURES}

Figure

Page

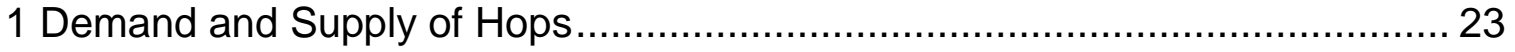

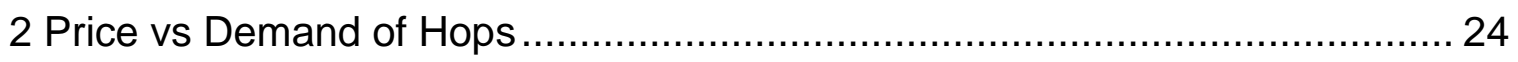

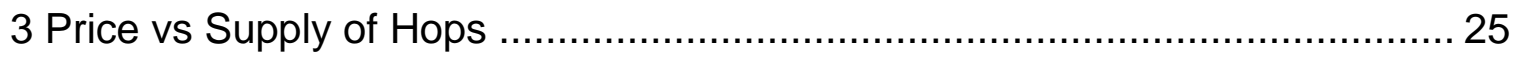

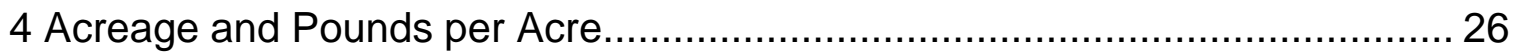




\section{CHAPTER 1}

\section{INTRODUCTION}

The malty, carbonated beverage beer has been a staple of human cultures and diets for thousands of years. From its health benefits, nutritious ingredients, and the social aspect of having a "cold one" after work, beer is a part of traditional fabrics around the word. People have worked diligently to perfect the production, distribution, and storage of beer.

One of the main ingredients to produce beer used by brewers is hops. The addition of hops is an important process in the making of these quality beers around the country, from the viewpoint of aroma, taste, and bitterness. The hop market in the United States is very intricate and tricky to monitor. The market follows a sort of roller coaster effect caused by either market shortages or surpluses. These fluctuations in hop supply drastically affect the market price and cause a stir in the allocation of hop acreage. This effect is magnified by the fact that growers have been experimenting with hop hybrids that are becoming more desirable to different brewers. Because more varieties are being added to the mix, the hop market is continually fluctuating up and down to accommodate the new and changing demands. These cause either shortages or surpluses that will affect future years. 
The earliest recorded known accounts of brewing come from ancient Babylon approximately around 6000 B.C. (Bamforth, 2003). Throughout the thousands of years beer has been consumed, the human population has turned to this beverage for many reasons. Among them are the fact that along with a basic diet of meat and bread, beer rounded out the necessary nutrients and vitamins required to survive. Beer contains B group vitamins such as biotin, nicotinic acid, pantothenic acid, pyridoxine, riboflavin, thiamine, folic acid, and vitamin $B_{12}$ (Hough, 1985). It also provided a safe source of water for consumption when local water sources were contaminated with infections or were unfit for drinking.

Because of the essential benefits beer provided it was a staple of traveler's diets; British ships sailing to the Americas were no exception. It was the Pilgrims who landed at Plymouth Rock who first brought beer to North America, and the first recorded brewery to be founded was in Lower Manhattan in 1632 (Bamforth, 2003). Beer played an important role as a source of clean water and beneficial nutrients for the colonists when they came to the Americas, which allowed them to survive and expand, eventually leading to the American Revolution and the birth of a nation.

During the nineteenth century the brewing industry boomed and by 1873 it had expanded to over 4,000 breweries nationwide. However, by the end of World War I, the industry had undergone overall consolidation resulting in approximately half as many breweries, but producing a much larger quantity of barrels per remaining brewery than in the previous century (Bamforth, 2003). By 
the start of the twentieth century the modern day Mega-breweries had already been founded and were on their way to market dominance. Among these are the commonly known companies: Anheuser-Busch, Miller, Coors, and Stroh.

As the brewing industry in the United States continued to grow, it did encounter a major obstruction during the earlier 1900's in the form of prohibition. On January 17, 1920, the United States Congress enacted the eighteenth amendment to the Constitution, which forbade the manufacture, sale, and transportation of intoxicating alcohols (Bamforth, 2003). This crushing blow to the brewing industry led to an enormous increase in illegal manufacturing and consumption of beer. Once Prohibition was lifted in 1933 by the twenty-first amendment to the US Constitution, many of the previous breweries had been crippled beyond repair, and only the larger breweries remained who took advantage of the situation by capturing a vast majority of the market share.

After Prohibition the US brewing industry remained dominated by the larger breweries which produced mostly light lager style beers. These beers were less in alcohol by volume (ABV), and used less expensive adjunct ingredients such as corn and rice. To many, these beers were bland and lacked the many complex characteristics needed to truly be an enjoyable beer. Despite Prohibition having been over for almost half a century, the act of home brewing was still illegal in the 1970's. However, in 1979 the federal government legalized home beer making (Gump, 1993). The legalization of home brewing paved the road for beer enthusiasts who were tired of traditional beer to take matters into their own hands and start what has become known as the Craft Brew Revolution. 
This revolution is the movement of newly founded micro-breweries tearing away from the mass produced, adjunct-filled beer of large corporations. These smaller breweries throughout the nation are focusing on the age-old methodology of quality, not quantity. Many of these breweries' founders started as home brewers whose ambition to create better tasting beer was given life by the legalization of home brewing, and their distaste of the quality of the products provided by larger breweries. Many craft breweries often use clever, hilarious, and sometimes bawdy names and labels for their product which exemplifies the humor, good-nature, and free-spirited imagination and enthusiasm of these brewers (Gump, 1993).

Although craft breweries consist of a small portion of the beer market, their influence and production continues to increase. The amount of hops used per barrel has increased drastically over the last few decades, far surpassing the rate of hops per barrel of the beer produced by large, mostly light lager producing breweries. Also, the process to determine what hop varieties to cultivate and in what amount has become more complex. Despite the increase of support for craft breweries, craft beer only accounted for $6 \%$ of beer sales in the United States in 2011 (Hieronymus, 2013).

\section{$\underline{\text { Problem Statement }}$}

There are few past studies that have been conducted to determine the econometric supply and demand model for US hops. In response to the 
increasing craft brewery segment, it is important that a new model be created in order to analyze the market.

\title{
$\underline{\text { Hypothesis }}$
}

There is a positive relationship between the quantity of hops supplied and demanded with hop acreage allocation, rainfall, beer production, and craft beer industry growth.

\section{$\underline{\text { Objectives }}$}

1. To create an econometric model of supply and demand of hops in the United States from 1981 to 2012.

2. To identify important exogenous variables that explain the supply and demand of hops using two-stage least squares.

\author{
Justification
}

As previously mentioned, although craft breweries consist of a small portion of the beer market share, their influence and production continues to increase. The amount of hops used per barrel has increased drastically over the last few decades, and the process to determine what hop varieties to cultivate and in what amount has become more complex. 
Over the past decade, the United States has decreased its total volume of exported hops from $80 \%$ to approximately $50 \%$. Despite craft breweries only controlling $6 \%$ of the US beer market by volume, the remainder of domestic hops are equally divided by the craft and mainstream breweries. Because of the continued increase of craft breweries and their use of pounds of hops per barrel has increased, the overall demand for hops has gone up. However, with the advancement of hop plant agronomics, the yields of new varieties have increased as well, causing large surpluses over the past several years. These surpluses have set market prices at rock bottom, and have filled warehouses to the brim (Barth Report, 2013).

Overall, in the past few years, the United States has been reducing the high alpha segment in favor of cultivating aroma varieties. The largest shift being present in the transition between 2012 and 2013 with an increase of approximately 3500 acres of aromatic hop varieties. Craft brewers, when buying hops, are more concerned with quality and aroma diversity than with price. This is another contributing factor to why there has been such an interest in hop breeding to create new varieties. The United States plays host to 55 different varieties of hops, which is 28 more than the second highest country Germany (Barth Report, 2013).

Because new varieties are continuously being bred in search for the perfect balance of characteristics, the supply and demand has been shifting over the last several years. It is essential that these changes be monitored and analyzed in order to determine which varieties are most certain to have a future 
in the craft brew industry. This constant roller coaster-like effect of the hop market could potentially create an imbalanced state, causing excess costs to relay from the growers all the way down to the end consumer.

Another reason that this study is important is because of the lack of economic analysis geared specifically towards the hop market. There have been many studies performed on the supply and demand model of beer in the United States. Studies such as Tremblay (2005) go into detail on the marketing and advertising of beer, as well as the economic evolution and conditions of the beer market from 1950 to 2000 . Despite the validity of this study, it focuses specifically on the beer market, not the market of hops. 


\section{CHAPTER 2}

\section{LITERATURE REVIEW}

Since the start of the Craft Brew Revolution, both growers of hops and brewers have evaluated the hop market and beer production in many different perspectives. However, a study analyzing an econometric model revolving around supply and demand does not exist.

The first section of this chapter covers a brief overview of the beer making process in order to understand all the ingredients and methodology required to brew beer. The second section of this chapter goes into more detail about the ingredient in question: hops. This section will discuss how hops are used and what their characteristics impart on the final product. The third section of this chapter will discuss previous research done on the marketing of hops, and the econometric studies performed in terms of land allocation as well as supply and demand equilibrium. The fourth section of this chapter will discuss the hop marketing order which was put into place in 1966, as well as the attempt to reestablish one in the early 2000's. This section will also look at a study conducted to analyze the effectiveness of the marketing order. The fifth section of the chapter will discuss other agricultural factors that may affect the hop market. The sixth and final section of this chapter will discuss an overview of econometric studies performed that relate to the analysis used in this paper. 


\section{Beer Making Process}

The basic ingredients to make beer are water, malts, hops, and yeast. As the Craft Brew Revolution began to expand, brewers started experimenting with different and interesting types of ingredients. Despite the new experimentation among craft brewers, the basic method of brewing beer has not changed (Bamforth, 2003).

At the simplest level, malting and brewing are the conversion of starches into alcohol. Brewers strive to obtain the maximum efficiency possible of converting these starches while maintaining a high level of quality and consistency (Bamforth, 2003). Malting is the process of spreading barley on a flat surface, spraying them with water, and once germination has taken place, drying them to a specified moisture content (Hough, 1985).

After the malting process has been completed, the grains are milled into a fine powder and then mashed in warm water, allowing them to steep. This solution known as the "wort" is then sent to the kettle to be boiled. It is in the boiling stage that hops are added incrementally. Once the boiling stage has been completed, the wort is cooled down to below at least $85^{\circ} \mathrm{F}$ in order for the yeast to be added. The mixture is then placed in a tank for fermentation to take place. After fermentation, the beer is ready to be packaged and distributed (Bamforth, 2003). 


\section{$\underline{\text { Hops }}$}

The use of hops appears to have been recognized during the twelfth century, and their use in beer is said to have had its origin in Germany (Findlay, 1971). Hops, Humulus Lupulus, is a member of the Humulus genus which is in the Cannabaceae family. Hops are used in beer production because of their several contributions to the final product. Among these are: bitterness, aroma, flavor, mouth feel, foam and lacing, flavor stability, and anti-microbial characteristics which inhibit the growth of organisms that could produce off flavors, aromas, or spoil the beer entirely (Hieronymus, 2013).

The harvested part of the hop plant is the flowering female cone which contains resins and hop oils that contribute both $\alpha$-acids and $\beta$-acids. It is these acids that impart bitterness and aroma on a beer's final character. Today, based on a hops acid level, it is very common to be classified as either an aroma or bittering hop (Hieronymus, 2013).

In the United States hops are grown mostly in the three northwestern states of Washington, Oregon, and Idaho. The climate of this region has proven to be ideal for growing hops and produces the vast majority of the United States' annual output. Once harvested, the hops are dried, and can be baled, frozen, and stored to await transport (Hieronymus, 2013).

During the nineteenth century a hop grower could only expect a full yield every ten to twenty years. This poor yielding led to a large excess of acreage being cultivated, which caused large surpluses in good years, and huge shortages in drought years. This caused massive price swings which continues 
to be a common theme today. To combat these problems, hop breeders have been creating hybrids which focus on finding plants that yield well, are less susceptible to diseases and damage, and can be easily harvested and stored. This method of breeding has led to many new and complex varieties of hops (Hieronymus, 2013).

\section{Foreign Studies on Hops}

There have been many studies conducted on the actual science behind growing, harvesting, and using hops in the process of brewing. There have been far fewer studies done on the marketing and structuring of hop supply and demand. Of the research that has been conducted on the business side of hops, one researcher in particular, Brian W. Ilbery, has conducted several studies in the area.

Ilbery conducted the research and analysis off his studies based in the UK during the 1980's, after an increase in the hop industry in the United States. Ilbery (1982) and Ilbery (1983a) were studies conducted whose objectives were to analyze the goals and attitudes of farmers as well as the decreasing size of the hop production in general. These studies were to better ascertain a more realistic explanation of farmer's economic behavior.

Ilbery (1983b) discusses how different attitudes and views of a farmer can affect their economic behavior. This study also examined how there are different variations in their behavior based on their age, education, experiences, and 
tradition. Due to increased production in foreign countries such as the United States and Germany, the UK put more emphasis on creating higher yields per hectare (llbery, 1983c). This study uses the basis of previous research conducted by Harvey (1963) to examine how other environmental factors, specifically soil, play a part in affecting the hop industry. Ilbery (1984) discusses how the hop market is in a state of flux, undergoing market changes over spans of decades. In order for the British market to progress forward, the industry must adapt its prices and production procedures.

Despite the validity of the studies conducted, they focus on the hop industry inside the UK, and the information is outdated, ranging back as far as thirty three years ago. Therefore it is necessary to revisit similar methods and analyze the current United States hop market in question.

\section{$\underline{\text { Hop Marketing Order }}$}

A marketing order is a marketing plan that the growers and handlers of a particular agricultural industry design and operate to work out solutions to general industry problems regarding supply and demand (The Role of Marketing orders, 1985). It is the Agricultural Marketing Agreement Act of 1937 that has allowed hop growers to coordinate their efforts in attempts to stabilize the market (Hallagan, 2008).

Folwell et al. (1985) is a study that was conducted with the goal of analyzing the hop marketing order. This study discussed how the order operated 
and if it had actually brought any significant benefits to the industry. Federal Marketing Order No 991 was approved on July 7, 1966 with the goal to improve hop producer welfare. The Hop Administrative Committee (HAC) projected future supply and demand estimates in attempts to help stabilize hop acreage and prices in order to reduce cyclical effects.

One of the powers granted from the order is volume control of salable product. This raised some controversy because there were those that saw this as a monopolistic advantage. Folwell et al. (1985) looks at how these volume control decisions are made, accuracy of these decisions, and the stabilization effects of HAC policies.

Because there are no substitutes for hops in its primary market, prices are inelastic and tend to have large price swings. Also, the start-up costs for growing hops are much higher compared to other crops. Due to these high volatility factors, the main responsibility of $\mathrm{HAC}$ is to recommend policies. Before March $1^{\text {st }}, \mathrm{HAC}$ and Handler Advisory Board (HAB) decide volume that can be marketed. These decisions are based on: prospective stock carry-in, desirable stock carry out, prospective imports and exports, anticipated consumption, and any other relevant factors (Folwell et al., 1985).

The HAC projects demand and amount of hops supplied other than domestic sources. The committee subtracts the difference to determine how much volume they will allow to be marketed. The HAC uses subjected projections based on trends, not on formal models. However, the marketing order does not have any authority on price setting. The HAC has been found to provide 
reasonably accurate estimates of total net supply. Although, it is difficult to determine if the marketing order has stabilized the market because of a lack of data due to two world wars, the great depression, prohibition, and a previous federal hop order. The HAC has ultimately recommended salable quantities that have caused expansion of the size of the market share (Folwell et al., 1985), despite the marketing order preventing new potential growers from entering the market (The Role of Marketing Orders, 1985).

Despite the apparent success of the marketing order, it was only in place until 1985, when it was repealed (Knudson, 2008). The hop industry operated free of a marketing order for the remainder of the century, and until a new proposition came forth in 2003. Chartier (2003) from the USDA Agricultural Marketing Service (AMS), discusses a newly proposed hop marketing order that would have taken effect during the 2005-2006 harvesting season. The newly proposed marketing order would have used allotments based on production during the harvesting seasons of 1997-2001. However, shortly after, the USDA announced that it was terminating the proceeding to establish a marketing order for hops. Agricultural Marketing Service (AMS) has determined that arguments have failed to demonstrate that: there is any need for a hop marketing order, that any such marketing order would have a positive impact on the industry, and that all of the benefits and costs associated with this process could be distributed equitably (Chartier G., 2005). 


\section{Other Agricultural Factors}

Among the factors that can affect the hop market is the price itself of hops. It is important to understand the decision making process of a farmer who may choose to either increase or decrease their given output. This change in production can be obtained through the advancement of planting more acreage, or decreasing the amount of acreage planted.

Laajimi et al. (2008) studied the supply response of peaches in Tunisia, in which it was found that changes in price was a direct factor in redistributing acreage allocation. Also, Ezekiel (1938) discusses the idea of agricultural entities operating under naïve expectation. This is the simple assumption that the current year's prices will continue on into the following year. This would lead to an increase in production following a year with higher prices, and a decrease in production following a year with lower prices. Either of these situations can cause further changes in price and lead the market away from an ideal equilibrium.

Another factor that can make a difference in agricultural production is rainfall. This is an uncontrollable factor that can either increase or decrease the product's yield. Burt et al. (1995) discusses how there is a direct relationship between water received and a plant's yield. However, if excessive water has been applied or received by the plant, yields may decline. This is due to diseases, poor aeration, cooler soil temperatures, and fertilizer leaching. 


\section{Studies on Econometric Analysis}

A very common method of analysis for agricultural commodities is ordinary least squares regression. Ordinary least squares regression uses the mathematical basis for the best fitting regression line for estimating the unknown parameters in a model with the goal of minimizing the differences between the observed responses (Evans, 2013). However, the consequences of applying ordinary least squares to a model, despite being unbiased, may be inefficient in estimating and contains invalid inference procedures (Johnston, 1971). For these reasons, the two-stage least squares approach is being used.

Simultaneous Equation Systems

Simultaneous equation models are certain models which consist of several equations, in which the behavior of the variables is jointly determined. In order for the simultaneous equation analysis to hold true, an equilibrium condition must be set in place, meaning that for the model, the quantity supplied and quantity demanded are set equal to each other (Pindyck, 1981). In scenarios, such as supply and demand, when ordinary least squares is applied, the results can become biased and yield an inconsistent coefficient value. The study done by Oyamakin et al. (2013), which analyzed the measurements of the heights of trees like the Gmelina Arborea, came across such inconsistencies and therefore applied the two-stage least squares method of analysis. 
Instrumental Variables Estimation by Two-Stage Least Squares

Angrist and Krueger (2001) shows that there has been analysis conducted since the 1920's, which was used to determine supply and demand elasticities and also later used in single equation models to correct for errors in measurements. When using ordinary least squares (OLS), the model will fail to provide accurate analysis when the explanatory variables are correlated to the error term. Therefore, two-stage least squares (2SLS) must be used to provide accuracy. Two-stage least squares is similar to OLS except that is uses two completely separate stages during the analysis phase in order to avoid problems with endogeneity. In the first stage, new variables are created using the instrument variables. The second stage is comprised of using the modelestimated values from the first stage and inserting them back into the original structural equations (Two-Stage Least Squares, 2SLS, Regression Analysis).

Goldstein and Khan (1978) looks into the supply and demand for exports, using a simultaneous approach similar to a two-stage least squares analysis. The study cites the importance of taking into account the explicit simultaneity that other studies can sometimes fail to address, which can lead to biased results. The study found that export price elasticities of demand are probably considerably larger than those obtained by previous researchers.

Astrom (2013) investigates the determinant factors of supply and demand of the silver market. The range of study was from the years 1973-2001, yielding only twenty-nine observations. This study created a supply and demand model incorporating several endogenous and exogenous factors. Using 2SLS, this 
study found that there were certain significant relationships between the exogenous factors in question with the structural supply and demand model. After performing the two stages of analysis, Astrom (2013) also performed a durbin Watson test to check for autocorrelation. 


\section{CHAPTER 3}

\section{METHODOLOGY}

In order to analyze the economic model for the hop market in the United States, the supply and demand model must first be created. There are several endogenous and exogenous variables to be collected. The endogenous variables, meaning internal to the system, are quantity of hops supplied, quantity of hops demanded, and the price of hops. The exogenous variable, meaning external to the system, are hop acreage allocation, the price of hops, rainfall, beer production, and craft beer industry growth. The data obtained for this study is secondary time series data ranging from 1981 to 2014 . The data for this study was collected from the Barth Reports, the Brewers Association, and the Yakima Airport Weather Warehouse. All of these sources, along with the sets of data can be found on the internet. The following sections of this chapter provides the procedures for data collection and procedures for data analysis.

\section{Procedures for Data Collection}

This paper will form the economic model using both endogenous and exogenous variables in order to map out the supply and demand functions for hops. Because there is a limitation on certain data sets, the form of the model takes shape as follows: 


$$
\begin{aligned}
& \text { Hopsqt }^{\mathrm{S}}=\mathrm{f}\left(\text { Hopspt}_{\mathrm{pt}} \text { Acrest, Rainfallt, } \varepsilon \mathrm{t}\right) \\
& \text { Hopsqt }^{\mathrm{D}}=\mathrm{f}\left(\text { Hopspt, Beert }_{\mathrm{t}} \text { Craftt, } \mu \mathrm{t}\right) \\
& \text { Hopsqt }_{\mathrm{t}}=\text { Hopsqt }^{\mathrm{S}}=\text { Hopsqt }^{\mathrm{D}}
\end{aligned}
$$

The third equation in the above group is the equilibrium condition in which

\begin{tabular}{|c|c|c|}
\hline Variable & Definition & Source \\
\hline \multicolumn{3}{|c|}{ Endogenous Variables } \\
\hline Hopsqt ${ }^{\mathrm{s}}$ & "Total quantity of hops supply (lb) & Barth Reports \\
\hline Hopsqt $^{\mathrm{D}}$ & Total quantity of hops demand (Ib) & Calculated \\
\hline Hopspt & Hops price $(\$ / \mathrm{lb})$ & $\begin{array}{l}\text { Brewers } \\
\text { Association }\end{array}$ \\
\hline \multicolumn{3}{|c|}{ Exogenous Variables } \\
\hline Acrest & Total US hop producing acres (Ac) & Barth Reports \\
\hline Rainfall $t$ & Annual Average Rainfall (in) & $\begin{array}{l}\text { Yakima Airport } \\
\text { Weather } \\
\text { Warehouse }\end{array}$ \\
\hline Beert & Annual US Beer Production (1000 gal) & Barth Reports \\
\hline Craft & Number of Craft Breweries & $\begin{array}{l}\text { Brewers } \\
\text { Association }\end{array}$ \\
\hline$\varepsilon \mathrm{t}, \mu_{\mathrm{t}}$ & Random disturbance terms & \\
\hline
\end{tabular}
the quantity of hops supplied is equal to the quantity of hops demanded.

Table 1 Description of Data and Sources

In this paper, the endogenous variables are the quantity of hops supplied, quantity of hops demanded, and the price of hops. The production of hops was gathered from the Barth Report, which is an annual publication supplied by the Barth-Haas Group. The Barth-Haas Group is the world's largest supplier of hop 
products and services. The Barth Report is an extensive global compilation of hop production by type and variety, along with many other factors that contribute to the hop market.

For this report, the Hopsqt $s$ variable represents the data collected for quantity of hops supplied which is broken down by state, type, and variety on an annual basis for the time period in question. The variable $\operatorname{Hops}_{\mathrm{qt}} \mathrm{D}$ represents the total quantity of hops demanded which was calculated by using the total hop produced as a base value. From this value the US demand was calculated by adding the amount of hops in previous storage that were consumed, along with the amount of hops that were imported that year. Once this value was obtained, the amount of hops that went into storage, along with the amount of hops that were exported, were subtracted. This calculated value gives a good representation of the quantity of hops demanded in the United States market. The Hopsqt variable represents the total quantity of hops which, because the market is in equilibrium, is equal to both $\mathrm{Hopsqt}^{\mathrm{S}}$ and $\mathrm{Hopsqt}^{\mathrm{D}}$.

The Hopspt variable represents the average annual price of hops in $\$ / \mathrm{lb}$. This data was collected from the Brewers Association. The Brewers Association is an organization comprised of both members from craft breweries and home brewers. The purpose of the Brewers Association is to promote and protect American craft brewers, their beers and the community of brewing enthusiasts.

The exogenous variables in this study include the amount of hop producing acres in the US, the average annual rainfall in the Yakima Valley, 
which contains approximately 75 percent of the US hop production, the annual US beer production, and the number of craft breweries in the US.

The variable Acrest represents the total hop producing acreage in the US. This data was collected from the Barth Reports, which provided an extensive break down of acreage allocation by state, type, and variety. The Rainfall $t$ variable represents the average annual rainfall in the Yakima Valley. Because this region contain a vast majority of the hops produced by the United States, it is a good representative area of how the weather impacts agricultural production.

The Beert variable represents the amount of beer produced in the US in thousands of gallons, which is the second most volume of beer produced in the world. This data was again collected from the comprehensive Barth Report. The last variable, Craft, represents the number of craft breweries in the US. This data variable was collected from the Brewers Association. The craft brewing segment has been increasing recently and there is a definite correlation between the increase of hop varieties, and the craft brewing segment.

Table 2 Descriptive Statistics of Variable Data

\begin{tabular}{|c|c|c|c|c|c|c|c|}
\hline Variable & Mean & StDev & Minimum & Q1 & Median & Q3 & Maximum \\
\hline Hops $_{\mathrm{qt}}$ & $59,027,798$ & $12,291,670$ & $35,297,020$ & $49,529,103$ & $56,555,719$ & $67,690,120$ & $97,262,721$ \\
\hline Hops $_{\mathrm{pt}}$ & 2.058 & 0.679 & 1.38 & 1.683 & 1.84 & 2.045 & 4.03 \\
\hline Acres $_{\mathrm{t}}$ & 35,254 & 5,828 & 25,103 & 29,604 & 35,012 & 41,494 & 44,189 \\
\hline Rainfall $_{\mathrm{t}}$ & 7.25 & 6.04 & 0.29 & 1.77 & 5.85 & 11.51 & 19.45 \\
\hline Beer $_{\mathrm{t}}$ & $6,135,581$ & 92,578 & $5,982,922$ & $6,063,936$ & $6,128,585$ & $6,224,638$ & $6,313,584$ \\
\hline Craft $_{\mathrm{t}}$ & 1,039 & 825 & 10 & 166 & 1,362 & 1,622 & 2,731 \\
\hline
\end{tabular}

The above table is comprised of the descriptive statistics for the raw data of the variables that will be analyzed. Descriptive statistics are important to 
include in quantitative analysis because it gives a quick and simple description of the data set at hand. From this table we can quickly see the basic information regarding the data such as the ranges, the mean, and the standard deviations.

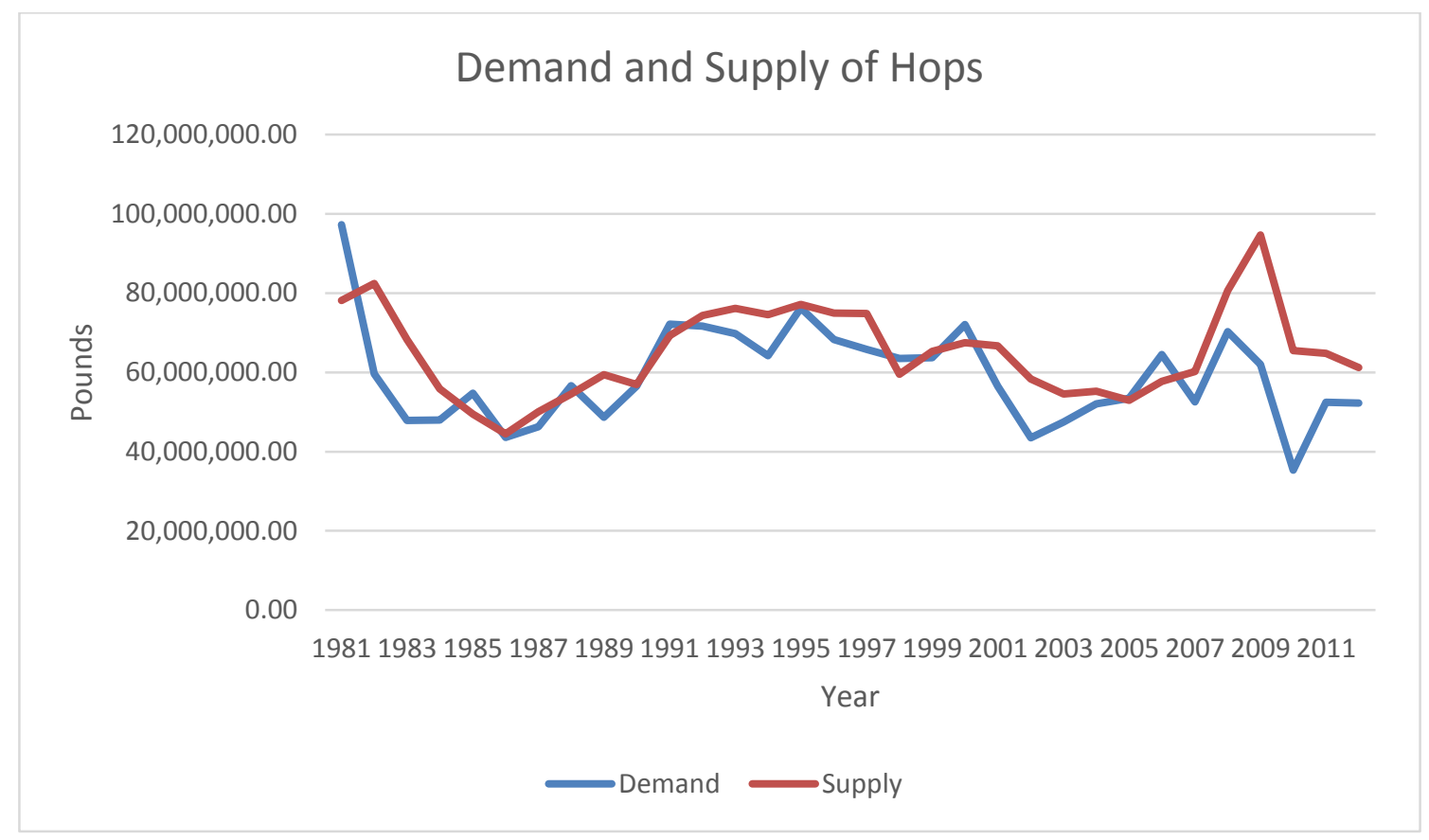

Figure 1 Demand and Supply of Hops

Figure 1 is a graph that shows the demand and supply of hops in pounds for the range of years being studied in the project. It can be seen that overall supply is larger than the demand. On years that the US demand exceeds the US supply, the market fulfills its needs by turning to either imports or to hops in storage from previous years. 


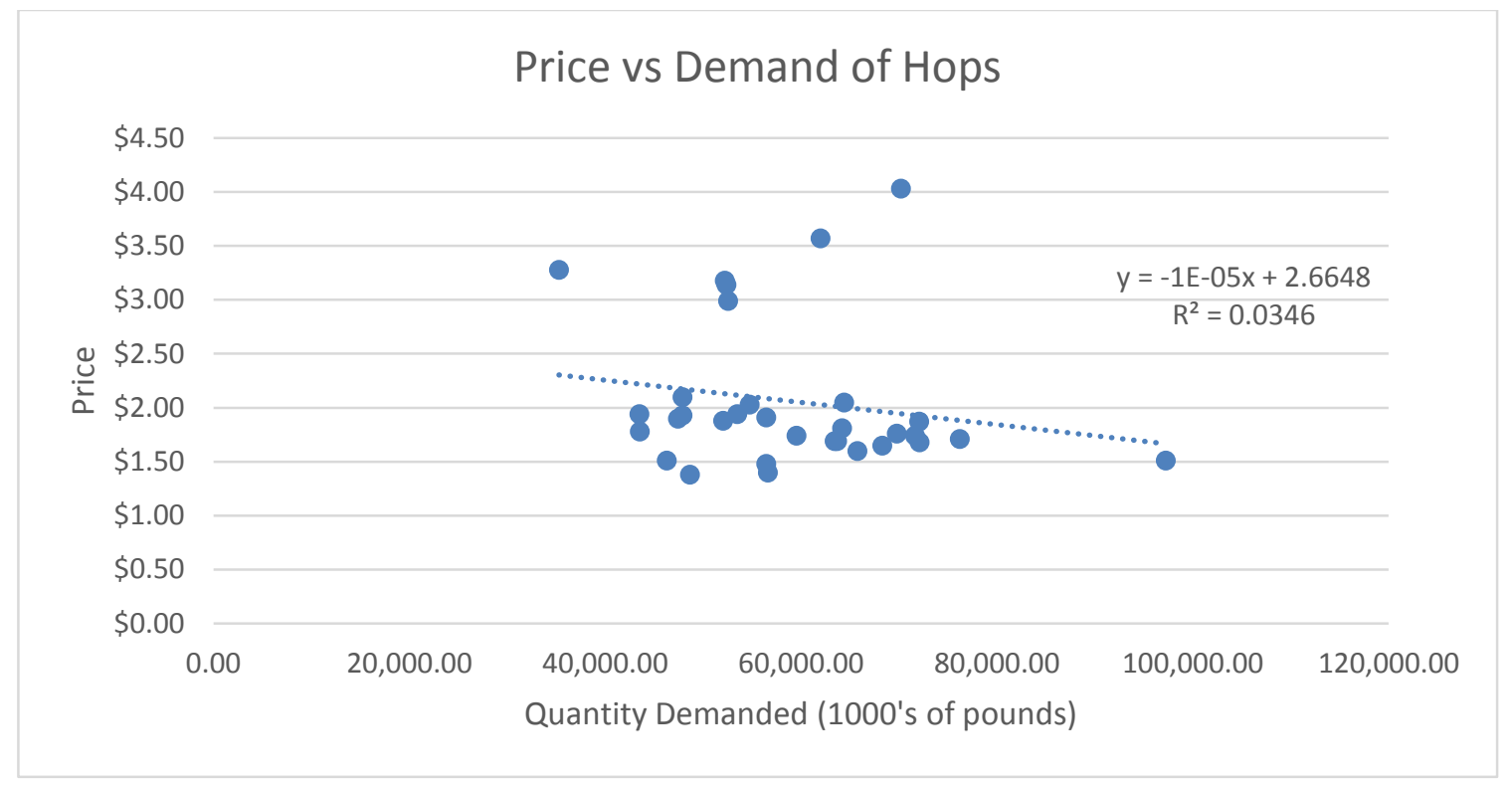

Figure 2 Price vs Demand of Hops

The above figure shows hop price versus the demand of hops. It is to be expected that the trend line is negative, because the higher the price, the less the quantity demanded will be. This is because if the price increases too much then it will deter potential buyers from the market. However, because of the quality mind set of the craft industry, increases in the price of hops does not deter that many potential buyers. 


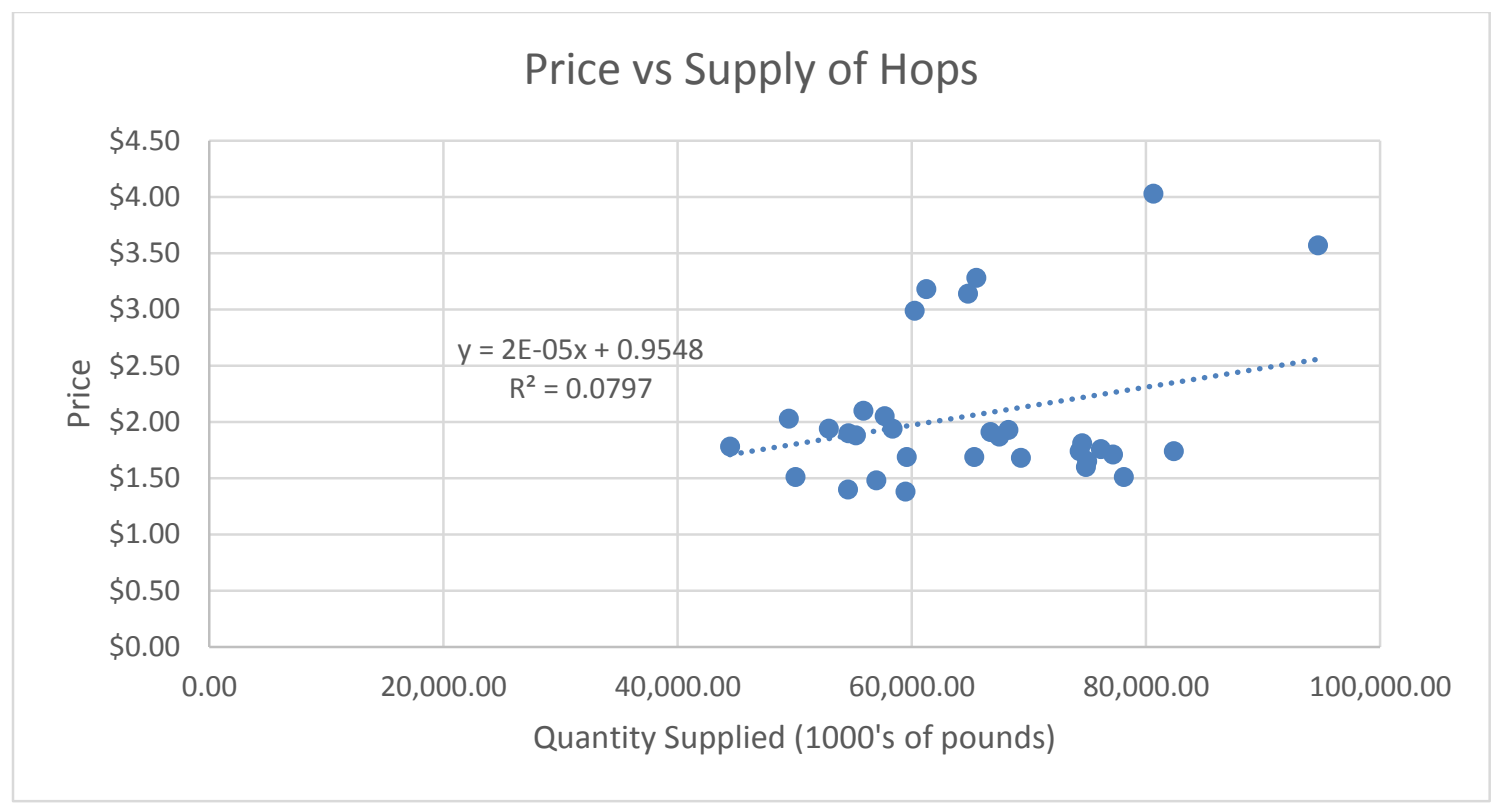

Figure 3 Price vs Supply of Hops

The above figure shows hop price versus the supply of hops. It is to be expected that the trend line is positive, because the higher the price, the more the quantity supplied will be. This is because when there are higher prices, suppliers want to increase their total output so they can attempt to maximize their profits with high prices and high volumes. However, because hops are not a first year bearing crop, there is some delay in this process. 


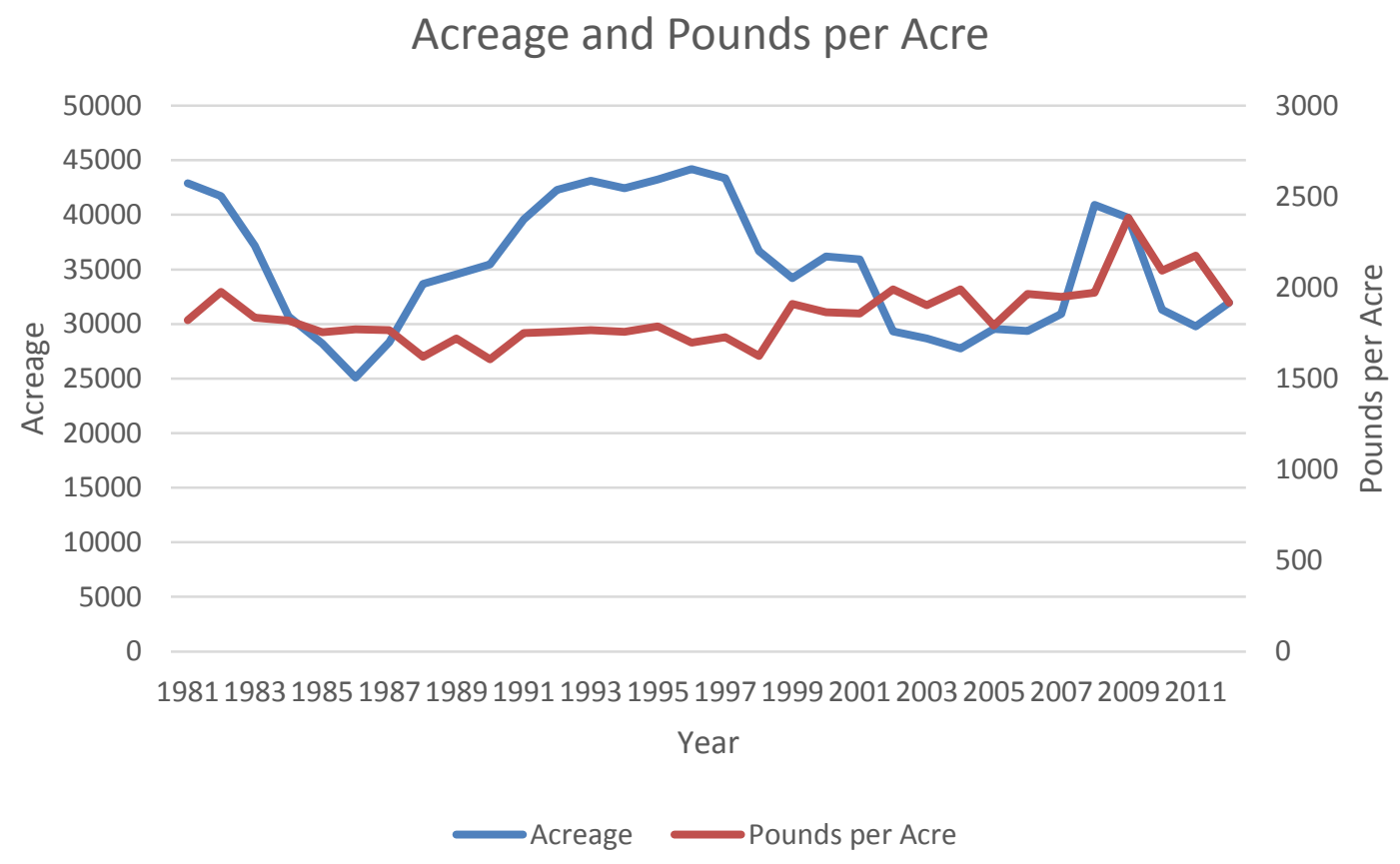

Figure 4 Acreage and Pounds per Acre

It can be seen in Figure 4 that the overall acreage has decreased slightly in three decades, and the yield per acre has been increasing slightly. This is due to the fact that researchers have been developing new varieties that have higher yields which can lead to surpluses. These surpluses over time have led to the downsizing by removal of acreage. With these new varieties, overall acreage is down, but the total yield is up.

\section{Procedures for Data Analysis}

The econometric analysis performed in this section will be conducted in four main phases. The first phase is the condition for identification, which is to see whether or not the two-stage least squares method is applicable for the 
analysis of this model. The second phase is to test for multicollinearity among each of the exogenous variables, in order to avoid biased and unstable estimates of each regression coefficient. The third phase involves solving the supply and demand system by estimating the instrumental variables using the 2SLS analysis. A Durbin-Watson test will be performed in order to check if there are any problems with autocorrelation. Autocorrelation is when there is correlation among successive observations over time. If there are any problems with autocorrelation, then the data will appear to fit better than it actually does, which means that certain data will appear significant. The fourth and final phase includes a Durbin Wu-Hausman test in order to check for any endogeneity problems. All of the statistical test that were performed were done so using the program Minitab 16.

Conditions for Identification

For the analysis of a complete system of simultaneous equations to be possible, the number of exogenous variables included in the whole equation system, but excluded from the equation that is being estimated must be equal or greater than the number of right-hand side endogenous variables in the equation that is being estimated (Astrom, 2013). The condition can be mathematically formulated as:

$$
M-m>d-1
$$

Where:

$M$ is the number of all the variables in the system $m$ is the number of all variables in the equation being considered 
$d$ is the number of all endogenous variables in the considered equation Multicollinearity Test

Multicollinearity is a condition occurring when two or more independent variables in the same regression model contain a high level of the same information (Evans, 2013). Because of two coefficients appearing more significantly related than they actually are, this leads to inaccurate and unreliable results. In order to test for the severity of multicollinearity, the variance inflation factor (VIF) is calculated. If the calculated value of VIF is greater than 5.0, then multicollinearity is considered to be a significant presence (Devinyak et al., 2012). To test for multicollinearity, two steps must be followed:

The first step is to run an OLS regression between all of the exogenous variables.

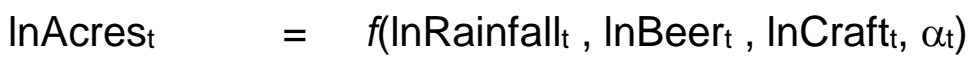

$$
\begin{aligned}
& \text { InRainfall }_{\mathrm{t}}=f\left(\text { InAcrest, InBeer }, \text { InCraft }, \beta_{\mathrm{t}}\right) \\
& \text { InBeer }_{t}=f\left(\text { InAcrest, InRainfall } l_{t}, \ln \text { Craft } t, \chi_{t}\right) \\
& \text { InCraft }=f\left(\ln \text { Acres }_{t}, \operatorname{InRainfa} l_{\mathrm{t}}, \operatorname{InBeer} \mathrm{t}, \delta_{\mathrm{t}}\right)
\end{aligned}
$$

$\alpha \mathrm{t}, \beta \mathrm{t}, \chi_{\mathrm{t}}, \delta_{\mathrm{t}}$ are the random disturbance terms

The second step is to calculate the VIF value. This value can be calculated with the following equation:

$$
\mathrm{VIF}=1 /\left(1-\mathrm{R}^{2}\right)
$$

Where:

$R^{2}$ is the $R$-squared value from the OLS regression between two variables 
If the VIF value exceeds 5.0, there is considered a significant amount of multicollinearity among the exogenous variables. This is because the VIF value is calculated from the R-squared value of the regression. For the VIF value to be above 5.0 , then the R-squared must be above 0.8 , meaning that there is a higher correlation among those variables.

Instrumental Variables Estimation by Two-Stage Least Squares and Autocorrelation Test

\section{Simultaneous Equations}

When analyzing simultaneous equations using OLS, the results will yield an inaccurate estimator. Therefore, to avoid this problem, the 2SLS method should be used (Oyamakin et al., 2013). To begin the simultaneous equations model, the supply and demand equations must be put into general form. In equations (5) and (6), the terms $Z^{S}$ and $Z^{D}$ are used to denote that the particular variables belongs to either the supply or demand equation. The random disturbance terms $\varepsilon_{t}$ and $\mu_{\mathrm{t}}$ represent the various unmeasured factors that have had an effect on the model.

General Form of Simultaneous Equations:

Demand Model

$$
Q_{t}^{D_{t}}=\alpha_{0}+\alpha_{1} P_{t}+\alpha_{2} Z_{t}+\varepsilon t
$$

Supply Model

$$
Q^{S_{t}}=\beta_{0}+\beta_{1} P_{t}+\beta_{2} Z S_{t}+\mu t
$$

Because we are assuming that the market is in equilibrium, we can write equation (7) as: 


$$
Q_{t}=Q_{t}^{D_{t}}=Q_{t}^{S_{t}}
$$

The variables are transformed into natural logarithmic form in order to interpret the coefficients as elasticities:

Demand Equation

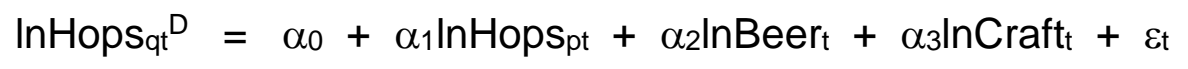

Supply Equation

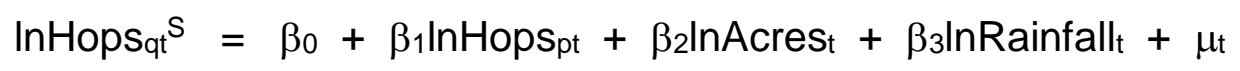

Equilibrium Equation

$$
\operatorname{InHopsqt}^{\mathrm{D}}=\operatorname{InHops}_{\mathrm{qt}} \mathrm{S}=\operatorname{InHops} \mathrm{qt}
$$

In equations (8), (9), and (10), each term represents the natural logarithm of each endogenous and exogenous variable of the model.

\section{Instrumental Variables Estimation by Two-Stage Least Squares}

2SLS performs regression analysis similarly to OLS, except it performs the regression in two separate stages. This process helps to avoid problems with endogeneity as the system of supply and demand equations are solved. In the first stage, the reduced form is estimated, and the endogenous variable, price, is regressed along all exogenous variables in the system. In the second stage, the fitted price value that was estimated in the first stage is then substituted back into the structural equations. Then another regression is performed which yields and unbiased, more accurate result (Astrom, 2013).

\section{First Stage}

The first stage of 2SLS involves identifying the endogenous variable that is causing issues, which in this study is InHopspt. For this part of the analysis, all 
of the exogenous variables in the system of equations are used as instrumental variables to estimate the equilibrium price equation in its reduced form. This is done by regression InHopspt on all of the instrumental variables (Astrom, 2013).

Equilibrium Price Equation

$\ln$ Hopspt $_{2} \alpha_{0}+\alpha_{1} \ln$ Acres $_{t}+\alpha_{2} \ln$ Rainfall $_{t}+\alpha_{3} \operatorname{lnBeer_{t}}+\alpha_{4} \operatorname{lnCraft} t+\varepsilon t$

After running this OLS regression, a new variable, InEstpt, is formed in order to run a regression in stage two.

\section{Second Stage}

In the second stage of the analysis, the newly created instrumental variable is substituted into the original structural equation (8) and (9). Once InHopspt is replaced by InEstpt, the OLS regression can be ran to solve the system of equations as follows:

Demand Equation

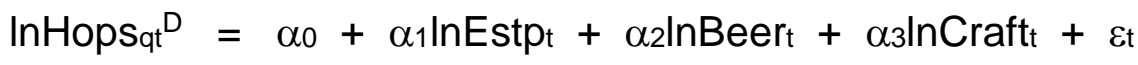

Supply Equation

$$
\operatorname{InHopsqt}^{S}=\beta_{0}+\beta_{1} \ln E_{s t p}+\beta_{2} \text { InAcrest }+\beta_{3} \text { InRainfall }+\mu \mathrm{t}
$$

The results yielded from the OLS regression of the transformed structural equations will be consistent, unbiased, and accurate estimates of the variables affecting the supply and demand of hops. 


\section{Autocorrelation Problem}

The problem autocorrelation, sometimes referred to as serial correlation, is when there is correlation among successive observations over time. This can be possible when a current residual is correlated with a past residual (Evans, 2013). If there is a presence of autocorrelation, then:

$$
\operatorname{Cov}(\varepsilon t, \varepsilon t-s)=E(\varepsilon t, \varepsilon t-s) \neq 0 \text { for } s>1
$$

\section{Durbin-Watson Test}

Autocorrelation can be evaluated more formally using a statistical test based on a measure called the Durbin-Watson statistic (Evans, 2013). The Durbin-Watson statistic is:

$$
\mathrm{D}=\Sigma(\varepsilon i-\varepsilon i-1)^{2} / \Sigma\left(\varepsilon^{2}\right)
$$

This is a ratio of the squared differences in successive residuals to the sum of the squares of all the residuals. The value of statistic $D$ will range from 0 to 4 , with 0 being positively autocorrelated and 4 being negatively autocorrelated (Evans, 2013). 
Table 3 Durbin-Watson Test criterion

\begin{tabular}{|l|l|}
\hline \multicolumn{1}{|c|}{ Condition } & \multicolumn{1}{c|}{ Results } \\
\hline $0<D<d L$ & $\begin{array}{l}\text { Positive } \\
\text { Autocorrelation }\end{array}$ \\
\hline$d L<D<d u$ & Inconclusive \\
\hline $4-d L<D<4$ & $\begin{array}{l}\text { Negative } \\
\text { Autocorrelation }\end{array}$ \\
\hline $4-d u<D<4-d L$ & Inconclusive \\
\hline$d u<D<4-d L$ & No Autocorrelation \\
\hline
\end{tabular}

As shown in Table 2, the critical value bordering the ranges are $d\llcorner$ and $d u$. These critical values are taken from the Durbin-Watson significance tables based on how many observations (n), and number of regressers (k), excluding the intercept, are run in the regression (Savin).

Endogeneity Test

Problems with endogeneity can occur in a system of equations such as supply and demand models when there are more than one endogenous variable. For this particular study, the two endogenous variables are price and quantity. The method used to solve the system of equations simultaneously and attempt to avoid an endogeneity problem is to use the 2SLS method. However, an endogeneity problem may still exist. The way to test for this problem is to perform a Durbin-Wu-Hausman test (Nakamura, 1981). The steps to perform this test are as follows:

1. Obtain the residuals from the estimated reduced form equilibrium equation price model from the first stage.

2. Add the residuals to the structural model as an explanatory variable. 
3. Perform the estimate of the structural model; there is an endogeneity problem if the residual coefficient is statistically significant.

\section{Assumptions and Limitations}

The assumption of this paper is that there will be no major changes in the hop market moving into the future that would drastically affect the market. It is assumed that there will continue to be a demand for hops and that the production of this product does not suddenly disappear. Also, there is the assumption that the market will clear. Meaning that the quantity supplied is equal to the quantity demanded.

The limitations of a project such as this is that there are few data observations to analyze. There may also be missing data among the sets used, and more well-suited data for this paper may be un-obtainable. It is important to analyze the data appropriately so as to not run into problems involving multicollinearity, autoregression, and endogeneity. 


\section{CHAPTER 4}

\section{RESULTS}

This chapter discusses the results of the tests performed based on the methods described in the procedures for data analysis in the previous chapter.

\section{Conditions for Identification}

The condition for identification step is used to determine if the two-stage least squares method is applicable to the system of equations. For this study, the identification check was performed as follows:

For the demand model, the total number of variables in the system (M) is 6: Hopsqt, Hopspt, Acrest, Rainfallt, Beert, and Craft. The total number of variables in the demand equation $(m)$ is 4: Hopsqt, Hopspt, Beert, and Craftt. The number of endogenous variables in the demand equation (d) is 2: Beert, and Craftt. The calculation of the order condition is as follows:

$$
\begin{aligned}
6-4 & \geq 2-1 \\
2 & \geq 1
\end{aligned}
$$

The condition for the demand equation has been met, and is therefore identified.

For the supply model, the total number of variables in the system $(M)$ is 6 : Hopsqt, Hopspt, Acrest, Rainfallt, Beert, and Craftt. The total number of variables in the supply equation (m) is 4: Hopsqt, Hopspt, Acrest, and Rainfallt. The number of 
endogenous variables in the supply equation (d) is 2 : Acrest, and Rainfallt. The calculation of the order condition is as follows:

$$
\begin{aligned}
6-4 & \geq 2-1 \\
2 & \geq 1
\end{aligned}
$$

The condition for the supply equation has been met, and is therefore identified. The test for identification has shown that the demand and supply equation have been properly identified. Therefore the method of two-stage least squares can be applied.

\section{$\underline{\text { Multicollinearity Test }}$}

The multicollinearity test was performed to ensure that none of the independent variables in the model contained high levels of the same information which would lead to a biased and inaccurate result. The variance inflation factors were calculated and are shown in Table 3.

Table 4 Results of Multicollinearity Test

\begin{tabular}{|l|r|c|}
\hline Variables & R-square & VIF \\
\hline InAcres $_{\mathrm{t}}$ & 0.284 & 1.397 \\
\hline InRainfall $_{\mathrm{t}}$ & 0.102 & 1.114 \\
\hline InBeer $_{\mathrm{t}}$ & 0.372 & 1.592 \\
\hline InCraftt & 0.223 & 1.287 \\
\hline
\end{tabular}

All of the VIF values are well below 5.0, therefore there is no significant presence of multicollinearity among the exogenous variables in the system of equations. 
$\underline{\text { Instrumental Variables Estimation by Two-Stage Least Squares and }}$

\section{$\underline{\text { Autocorrelation Test }}$}

First Stage

The variables in this study that creates a biased and inaccurate result is the endogenous variable Hopspt. By using the OLS estimation method, the equilibrium price equation was formulated as follows:

$$
\operatorname{InHopspt}=\alpha_{0}+\alpha_{1} \operatorname{lnAcrest}+\alpha_{2} \ln \text { Rainfall }_{t}+\alpha_{3} \ln \text { Beer }_{t}+\alpha_{4} \ln \operatorname{nraft}_{t}+\varepsilon t
$$

Table 5 Results of Equilibrium Price Equation

\begin{tabular}{|c|c|c|c|c|}
\hline \multicolumn{5}{|c|}{$\begin{array}{l}\text { Dependent Variable: InHopspt } \\
\text { Observations: } 32\end{array}$} \\
\hline Variable & Coefficient & \begin{tabular}{|l|} 
Std. \\
Error
\end{tabular} & t-Statistic & Prob. \\
\hline Constant & 218.57 & 45.41 & 4.81 & 0.000 \\
\hline InAcrest & 0.4192 & 0.2533 & 1.65 & 0.110 \\
\hline InRainfallt & -0.1371 & 0.0292 & -1.27 & 0.215 \\
\hline InBeert & -14.263 & 2.995 & -4.76 & 0.000 \\
\hline InCraftt & 0.1141 & 0.0231 & 4.95 & 0.000 \\
\hline $\begin{array}{l}\text { R-squared } \\
\text { Adjusted R-squared }\end{array}$ & $\begin{array}{l}0.564 \\
0.499\end{array}$ & \multicolumn{2}{|c|}{$\begin{array}{l}\text { Durbin-Watson } \\
\text { dL: } 0.978 \\
\text { du: } 1.509\end{array}$} & 1.042 \\
\hline
\end{tabular}

As the results show in the table, for every one percent change in hops acreage, Yakima's annual precipitation, US beer production, and number of US craft breweries, the price of hops will change by $0.42,-0.14,-14.26$, and 0.11 percent, respectively. Because beer production and number of craft breweries both have a p-value of 0.000 , we can reject the null hypothesis that at the 0.01 level of significance, the true parameter is equal to zero. Therefore, US beer 
production and US craft breweries are significant at the one percent level. However, the acreage and rainfall variables have $p$-values of 0.110 and 0.215 respectively. Thus, we fail to reject the null hypothesis that at the 0.1 level of significance, the true parameter is equal to zero. Therefore these two variables have no significant value. Also, the Durbin-Watson statistic is 1.042 , which is in the range of being inconclusive about having autocorrelation.

Running the OLS regression of the price of hops against all the exogenous variables, yielded the new variable InEstpt. This new variable can be written as:

InEstp $t=218.57+0.4192^{*} \operatorname{InAcres} t+-0.1371^{*} \operatorname{InRainfall} t+-14.263^{*} \operatorname{InBeer}_{t}+$ $0.1141^{*} \ln C r a f t t$

Second Stage

The second stage of analysis involved estimating the structural model using the explanatory endogenous variable InEstpt. By using the OLS regression method, the structural demand model is as follows:

Demand Equation

$$
\operatorname{InHopsqt}^{\mathrm{D}}=\alpha_{0}+\alpha_{1} \operatorname{lnEstp_{t}}+\alpha_{2} \operatorname{lnBeer} t+\alpha_{3} \operatorname{lnCraft} t+\varepsilon t
$$


Table 6 Results of Demand Equation

\begin{tabular}{|l|c|c|c|c|}
\hline $\begin{array}{l}\text { Dependent Variable: InHopsqt } \\
\text { Observations: } 32\end{array}$ \\
\hline \multicolumn{1}{|c|}{ Variable } & Coefficient & $\begin{array}{l}\text { Std. } \\
\text { Error }\end{array}$ & t-Statistic & Prob. \\
\hline Constant & -79.62 & 49.39 & -1.61 & 0.118 \\
\hline InEstp $t$ & 0.0369 & 0.205 & 0.18 & 0.859 \\
\hline InBeert & 6.246 & 3.162 & 1.98 & 0.058 \\
\hline InCraftt & -0.021 & 0.026 & -0.78 & 0.441 \\
\hline $\begin{array}{l}\text { R-squared } \\
\text { Adjusted R-squared }\end{array}$ & 0.171 & $\begin{array}{l}\text { Durbin-Watson } \\
\text { dL: } 1.039 \\
\text { du: } 1.428\end{array}$ \\
\hline
\end{tabular}

The results from Table 4 shows the demand model for hops as follows: $\operatorname{InHopsqt}^{\mathrm{D}}=-79.62+0.0369^{*} \operatorname{InEstp} t+6.246^{*} \operatorname{InBeer}_{\mathrm{t}}-0.021^{*} \operatorname{InCraft}_{\mathrm{t}}$

The factor US beer production has a p-value of 0.058 , so we reject the null hypothesis that the true parameter is equal to zero at the 0.1 significance level. Therefore, the US beer production variable is significant at the 10 percent level. So for every 1 percent change in US beer production, there will be a 6.25 percent change in quantity of hops demanded in the same direction. The factors estimated price and number of craft breweries have $p$-values of 0.859 and 0.441 , respectively. So we fail to reject the null hypothesis at the 0.1 significance level. Therefore the two variables estimated price and number of craft breweries have no significance. Also, the Durbin-Watson statistic is 1.4646 , which falls in the range of not having autocorrelation. 
By using the OLS regression method, the structural demand model is as follows:

Supply Equation

$$
\operatorname{InHopsqt}^{S}=\beta_{0}+\beta_{1} \operatorname{lnEstp} t+\beta_{2} \operatorname{lnAcres} t+\beta_{3} \operatorname{lnRainfall} t+\mu t
$$

Table 7 Results of Supply Equation

\begin{tabular}{|c|c|c|c|c|}
\hline \multicolumn{5}{|c|}{$\begin{array}{l}\text { Dependent Variable: InHopsqt } \\
\text { Observations: } 32\end{array}$} \\
\hline Variable & Coefficient & Std. Error & t-Statistic & Prob. \\
\hline Constant & 8.589 & 1.672 & 5.14 & 0.000 \\
\hline InEstp & -0.05 & 0.1254 & -0.4 & 0.693 \\
\hline InAcrest & 0.889 & 0.1582 & 5.62 & 0.000 \\
\hline InRainfall $_{t}$ & 0.0097 & 0.02265 & 0.43 & 0.672 \\
\hline $\begin{array}{l}\text { R-squared } \\
\text { Adjusted R-squared }\end{array}$ & $\begin{array}{l}0.554 \\
0.506\end{array}$ & \multicolumn{2}{|c|}{$\begin{array}{l}\text { Durbin-Watson } \\
\text { dL: } 1.039 \\
\text { du: } 1.428\end{array}$} & 1.68348 \\
\hline
\end{tabular}

The results from Table 4 shows the demand model for hops as follows:

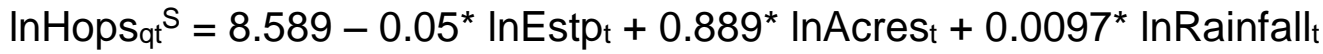

The factor of acreage has a p-value of 0.000 , so we reject the null hypothesis that the true parameter is equal to zero at the 0.01 significance level. Therefore, the US acreage variable is significant at the 1 percent level. So for every 1 percent change in US acreage, there will be a 0.889 percent change in quantity of hops supplied in the same direction. The factors estimated price and average annual rainfall have $p$-values of 0.963 and 0.672 , respectively. So we fail to reject the null hypothesis at the 0.1 significance level. Therefore the two variables estimated price and average annual rainfall have no significance. Also, 
the Durbin-Watson statistic is 1.68348 , which falls in the range of not having autocorrelation.

\section{Endogeneity Test}

In order to test for endogeneity, the Durbin-Wu-Hausman test will be performed. In order to perform this test, the residuals were obtained from the equilibrium price equation, and then inserted back into the structural model. The test for endogeneity of the demand model is as follows:

Demand Equation

$$
\begin{aligned}
& \operatorname{InHopsqt}{ }^{D}=\alpha_{0}+\alpha_{1} \operatorname{lnHopspt}+\alpha_{2} \ln A c r e s_{t}+\alpha_{3} \ln \text { Rainfall } t+ \\
& \alpha_{4} \operatorname{RESID} 1+\varepsilon \mathrm{t}
\end{aligned}
$$

\begin{tabular}{|c|c|c|c|c|}
\hline $\begin{array}{l}\text { Dependent Variable: } \\
\text { Observations: } 32\end{array}$ & opsqt & & & \\
\hline Variable & Coefficient & Std. Error & t-Statistic & Prob. \\
\hline Constant & -79.62 & 49.82 & -1.60 & 0.122 \\
\hline InEstpt & 0.0369 & 0.2071 & 0.18 & 0.860 \\
\hline InBeert & 6.245 & 3.189 & 1.96 & 0.061 \\
\hline InCraftt & -0.02056 & 0.02653 & -0.77 & 0.445 \\
\hline RESID1 & -0.1379 & 0.1912 & -0.72 & 0.477 \\
\hline $\begin{array}{l}\text { R-squared } \\
\text { Adjusted R-squared }\end{array}$ & $\begin{array}{l}0.186 \\
0.066\end{array}$ & $\begin{array}{l}\text { Durbin-l } \\
d \mathrm{~d}: 0.97 \\
\text { du: } 1.50\end{array}$ & & 1.4037 \\
\hline
\end{tabular}

Table 8 Results of Endogeneity Test of Demand Equation

Table 6 shows the results of the test for endogeneity of the demand model. The RESID1 variable has a p-value of 0.477 , which means that we fail to reject the null hypothesis that the true parameter is equal to zero at the 0.1 
significance level. Therefore the RESID1 factor is not significant and we can conclude that the demand equation does not have any endogeneity problems.

The test for endogeneity of the supply model is as follows:

Supply Equation

$$
\operatorname{InHopsqt}^{S}=\beta_{0}+\beta_{1} \operatorname{lnHopspt}+\beta_{2} \operatorname{lnBeert}+\beta_{3} \operatorname{lnCraft}+\beta_{4} \text { RESID1 }+\mu \mathrm{t}
$$

Table 9 Results of Endogeneity Test of Supply Equation

\begin{tabular}{|c|c|c|c|c|}
\hline \multicolumn{5}{|c|}{$\begin{array}{l}\text { Dependent Variable: InHopsqt } \\
\text { Observations: } 32\end{array}$} \\
\hline Variable & Coefficient & Std. Error & t-Statistic & Prob. \\
\hline Constant & 8.589 & 1.673 & 5.14 & 0.000 \\
\hline InEstp & -0.05 & 0.1254 & -0.4 & 0.693 \\
\hline InAcrest & 0.889 & 0.1582 & 5.62 & 0.000 \\
\hline InRainfall $_{t}$ & 0.0097 & 0.02265 & 0.43 & 0.672 \\
\hline RESID1 & -0.1379 & 0.1391 & -0.99 & 0.33 \\
\hline $\begin{array}{l}\text { R-squared } \\
\text { Adjusted R-squared }\end{array}$ & $\begin{array}{l}0.569 \\
0.505\end{array}$ & \multicolumn{2}{|c|}{$\begin{array}{l}\text { Durbin-Watson } \\
\mathrm{d}_{\mathrm{L}}: 1.039 \\
\text { du: } 1.428\end{array}$} & 1.6667 \\
\hline
\end{tabular}

Table 7 shows the results of the test for endogeneity of the supply model. The RESID1 variable has a p-value of 0.33 , which means that we fail to reject the null hypothesis that the true parameter is equal to zero at the 0.1 significance level. Therefore the RESID1 factor is not significant and we can conclude that the supply equation does not have any endogeneity problems. 


\section{CHAPTER 5}

\section{SUMMARY, CONCLUSIONS, AND RECOMMENDATIONS}

\section{Summary}

This paper has developed the demand and supply model for hops grown in the United States, and has determined relationships between the demand and supply of hops with its determinant factors. The data obtained for this study is secondary time series data ranging from 1981 to 2014 . The data for this study was collected from the Barth Reports, the Hopunion, and the Brewers Association.

The analysis performed for this study was done using the statistical software program Minitab 16. The analysis of this paper was conducted in four separate parts, the first of which was the condition for identification of the system of equations. This test yielded the results that the demand and supply equations were appropriate to conduct the two-stage least squares method. The second test performed was to check for multicollinearity amongst the exogenous variables. This was performed by running regressions of each exogenous variables against the other exogenous factors. From each regression, an Rsquared value was obtained which was then used to calculate the Variance Inflation Factor (VIF). Each variable yielded a VIF value less than the threshold value of 5.0 , which means that none of the factors contain multicollinearity. The 
third portion of the analysis involved the two stages used to perform the 2SLS method. The first stage in this section involved running a regression of the price factor against all of the exogenous variables. This regression was then used to create an estimated price variable which was then used in the second stage. The second stage took the estimated price value and substituted it back into the demand and supply models. Regressing the demand model showed that the US beer production variable is significant at the 10 percent level. So for every 1 percent change in US beer production, there will be a 6.25 percent change in quantity of hops demanded in the same direction. Regressing the supply model showed that the US acreage variable is significant at the 1 percent level. So for every 1 percent change in US acreage, there will be a 0.889 percent change in quantity of hops demanded in the same direction. The last section of analysis was conducted to determine if the model contained any endogeneity problems. This was done by obtaining the residuals from the equilibrium price model and putting them in the demand and supply models to see if there was any significance. For both the demand and supply models the residuals were not significant, meaning that the model does not contain any problems with endogeneity. 


\section{$\underline{\text { Conclusions }}$}

The results of this study shows that the demand model for hops yielded a positive relationship only with the factor United States beer production. The supply model also yielded only one significant factor, that being the United States acreage.

The demand model shows that quantity demanded is relatively inelastic to price with a coefficient value of 0.04 . This means that there is not that much change in quantity demanded when there is a more significant change in price. This is due to the fact that craft breweries consume a large portion of hops grown in the United States, and they are more geared towards quality rather than quantity. This means that craft breweries are more willing to purchase better varieties of hops regardless of large price swings, in order to create and maintain consistent products. Another reason for the inelasticity of hop price is due to the fact that there are no substitutes for hops in the beer making process.

One thing to note with the price coefficient of the demand model is that theoretically is should be negative. However, in this model the coefficient yielded a positive value. Despite this, the model makes sense because the coefficient is still extremely close to zero, and the standard error value makes up for the difference between the coefficient and zero.

The significant factor in the demand model, US beer production, makes sense and falls in line with the previous assumption. Because hops are one of the four main ingredients in making beer, and there are no viable substitutes, a 
positive relationship exists between the two. When there is a 1 percent change in the volume of beer produced in the United States, there is a 6.25 percent change in quantity of hops demanded in the same direction.

The final variable analyzed in this study, the number of craft breweries, did not however, yield a strong correlation to the quantity of hops demanded. This is due to the fact that despite craft breweries using substantially more pounds of hops per barrel than macro breweries, the larger breweries based on volume alone control more of the quantity of hops demanded. This also plays into the beer production variable, because large breweries produce over 80 percent of beer produced in the US.

The supply model also showed that the quantity supplied is inelastic in relation to price with a coefficient value of -0.05 . This is because hops are not a first year bearing crop. It takes multiple years for the plant to reach full production. Therefore, the farmers have to use their best judgment and predict which varieties will maximize profits in the future once the acreage has reached full production. Once a portion of land has been established, it will provide its annual yield regardless of the current price of hops. This is what makes it such a large and difficult decision for a grower to replant sections of the farm as a different variety. The new variety will have a few years of little or no production value, and the market conditions may even change again once the plants have reached maturity.

One thing to note with the price coefficient of the supply model is that theoretically is should be positive. However, in this model the coefficient yielded 
a negative value. Despite this, the model makes sense because the coefficient is still extremely close to zero, and the standard error value makes up for the difference between the coefficient and zero.

As expected, the factor acreage has a strong positive relationship with the quantity of hops supplied. Over the decades there have been technological advances in the agronomics of hop hybrids, which has led to an overall increase of hops yields per acre. This alongside the direct relationship acreage has with hop production has shown the obvious connection between the two.

The Northwestern region of the United States has proven to be an ideal location for growing hops due to its mild climate. The Yakima valley has proven this by being relatively dry in terms of precipitation, which has allowed hops to not be destroyed by diseases and pests that flourish in more wet areas. The farmers in this region have been able to provide water to their crops by utilizing the sources of irrigation water available from the other areas of the North West that do have much more wet climates. This is why the factor rainfall does not maintain a significant relationship in the model.

\section{$\underline{\text { Recommendations }}$}

This study has yielded results that should be viewed as an estimation of the econometric model of the demand and supply of hops in the United States. It is recommended that further research can be conducted in this area of study. 
One of the main limitations of this study has been data collection. Due to a lack of available data, the most appropriate factors that apply to this area of study may not have been used. Another limitation involved with the data collection is that it was all secondary data which may not be completely reliable. During collection, different sources were compared and in multiple cases they each yielded different values for the same variable. In the future, if more reliable data can be procured, the study can be conducted more accurately.

It is important to realize that the hop market has gone through many changes over the past few decades. Before the time period in question, a marketing order had been put in place and since then revoked. The hop market has seen many swings in demand and supply, which can be caused by factors other than those mentioned in this study.

Finally, the method formulated and used in this study can be manipulated to fit any set of data in order to create an econometric model of supply and demand for any commodity in the world. 


\section{REFERENCES}

Angrist, J., and Krueger, A. B. (2001). Instrumental variables and the search for identification: From supply and demand to natural experiments (No. w8456). National Bureau of Economic Research.

Åström, M. (2013). Supply and Demand of the Silver Market (Master's thesis). Retrieved April 5, 2015, from http://pure.Itu.se/portal/files/67780553/LTU-EX-2013-62059944.pdf

Bamforth, C. "Beer: Tap into the Art and Science of Brewing." New York: Oxford UP, 2003.

Burt, Charles, David H. Appling, and Linda Norton. "Water vs Fertilizer vs Yield." The Surface Irrigation Manual: A Comprehensive Guide to Design and Operation of Surface Irrigation Systems. Exeter, CA: Waterman Industries, 1995. 1.27. Print.

Chartier, George. "Agricultural Marketing Service - USDA Requests Alternatives to Proposed Hop Marketing Order before Hearing." Agricultural Marketing Service - USDA Requests Alternatives to Proposed Hop Marketing Order before Hearing. USDA, 1 July 2003. Web. 10 Apr. 2015.

Chartier, George. "Agricultural Marketing Service - USDA Terminates Proposed Hop Marketing Order Proceeding." Agricultural Marketing Service - USDA Terminates Proposed Hop Marketing Order Proceeding. USDA, 20 June 2005. Web. 10 Apr. 2015.

Devinyak, O. T., Mikh V. Slivka, Mar V. Slivka, V. M. Vais, and V. G. Lendel. "Quantitative Structure Activity Relationship Study and Directed Synthesis." Medicinal Chemistry Research 21.9 (2012): 2263-272. Web.

Evans, J.R. "Business Analytics: Methods, Models, and Decisions." Boston: Pearson, 2013.

Ezekiel, M. "The Cobweb Theorem." The Quarterly Journal of Economics 52.2 (1938): 255. Web.

Findlay, W.P.K. "Modern Brewing Technology." London: Macmillan, 1971.

Folwell, R.J. \& R.C. Mittelhammer \& F.L. Hoff \& P.K. Hennessy. "The Federal Hop Marketing Order and Volume-Control Behavior." Agricultural Economics Research 37.4 (1985): 17-32. http://econpapers.repec.org/article/agsueraer/149287.htm 
Gabrielyan, Gnel. Domestic and Export Price Formation of U.S. Hops.

Washington State University: School of Economic Sciences, 2012.

Galinato, Suzette P. \& Ann George \& Herbert Hinman, 2010. "2010 Estimated Cost of Producing Hops in the Yakima Valley, Washington State," Working Papers 2010-8, School of Economic Sciences, Washington State University.

Goldstein, Morris, and Mohsin S. Khan. "The Supply and Demand for Exports: A Simultaneous Approach." The Review of Economics and Statistics 60.2 (1978): 275-86. JSTOR. Web. 14 Apr. 2015.

Group, Barth-Haas. "The Barth Report." 1981-2012. http://www.barthhaasgroup. com/en/news-and-reports/the-barth-report-hops

Gump, B.H., and David J. Pruett. "Beer and Wine Production; Analysis, Characterization and Technological Advances." Washington: American Chemical Society, 1993.

Hallagan, William S. "Contracting Problems and the Adoption of Regulatory Cartels." Economic Inquiry 23 (1985): n. pag. Web. 9 Apr. 2015.

Hieronymus, S. "For the Love of Hops: The Practical Guide to Aroma, Bitterness, And the Culture of Hops." Boulder: Brewers Publications, 2012.

Hough, J.S. "The Biotechnology of Malting and Brewing." Cambridge University Press; Cambridge, 1985.

Ilbery, Brian W. "The Decline of Hop Growing in Hereford and Worcestershire." The Royal Geographical Society 14.3 (1982): 203-11. Web.

Ilbery, Brian W. "A Behavioral Analysis of Hop Farming in Hereford and Worcestershire." Geoforum 14.4 (1983): 447-449. Web.

Ilbery, Brian W. "Goals and Values of Hop Farmers." The Royal Geographical Society 8.3 (1983): 329-341. Web.

Ilbery, Brian W. "Harvey's Principles Reapplied: A Case Study of the Declining West Midland Hop Industry." Geoforum 14.1 (1983): 111-123. Web.

Ilbery, Brian W. "The Marketing of Hops in Great Britain: A Study of Changing Structures and Farmers' Attitudes." European Journal of Marketing 18.4 (1984): 45-55. Web. 
Johnston, J. "Simultaneous Equation Systems." Econometric Methods. Third ed. New York: McGraw-Hill, 1971. N. pag. Print.

Knudson, William A., and Hamish Gow. "Hopping Mad: The Impact of Hops Market Turmoil on the Specialty Beer Industry". Working paper no. 011209. Michigan: Strategic Marketing Institute, 2009. Print.

Laajimi, A., Guesmi, A., Mahfoudhi, A., and Dhehibi, B. (2008). "Analyzing supply response of fruit tree products in Tunisia: The case of peaches". Agricultural Economics Review, 9(1).

Nakamura, Alice, and Massao Nakamura. "On the Relationships Among Several Specification Error Tests Presented by Durbin, Wu, and Hausman." The Econometric Society 49.6 (1981): 1583-588. Web.

Oyamakin, S. O., Fajemila, A. D., and Abdullateef, S. (2013). "Parameter estimation of height-diameter relationships of Gmelina arborea Roxb.(Family Verbenaceae)". Retrieved March 31, 2015. http://www.scihub.org/ABJNA/PDF/2013/4/ABJNA-4-4-468-475.pdf

Pindyck, Robert Stephen., and Daniel L. Rubinfeld. "Simultaneous-Equation Estimation." Econometric Models and Economic Forecasts. New York: McGraw-Hill, 1981. 287-330. Print.

Savin. Durbin-Watson Significance Tables (n.d.): n. pag. Web. 20 Apr. 2015. $<$ https://www3.nd.edu/ wevans1/econ30331/Durbin_Watson_tables.pdf>.

Tremblay, Victor J., and Carol Horton, Tremblay. The U.S. Brewing industry: Data and Economic Analysis. Cambridge, MA: MIT, 2005. http://eh.net/bo Ok reviews/the-u-s-brewing-industry-data-and-econometric-analysis/

"Two-Stage Least Squares (2SLS) Regression Analysis - Statistics Solutions." Statistics Solutions. N.p., n.d. Web. 14 Apr. 2015. $<$ http://www.statisticssolutions.com/two-stage-least-squares-2slsregression-analysis/>.

United States. Congress. The Role of Marketing Orders in Establishing and Maintaining Orderly Condition. Report 85-87. Washington: GAO, 1985. U.S. Government Printing Office. April 10, 2015. Web.

"Weather Data for Yakima, WA." Weather Warehouse. N.p., n.d. Web. 6 Apr. 2015. <http://weather- warehouse.com/WeatherHistory /PastWeather Data_YakimaArptTerminal_Yakima_WA_January.html>. 
APPENDIX 1: Complete Data Set of Demand and Supply Model, 1981-2012.

\begin{tabular}{|c|c|c|c|c|c|c|}
\hline Year & Quantity (lb) & $\begin{array}{c}\text { Average } \\
\text { Hop } \\
\text { Price } \\
\text { (\$/lb) }\end{array}$ & $\begin{array}{c}\text { Total } \\
\text { Acreage (ac) }\end{array}$ & $\begin{array}{c}\text { Yakima } \\
\text { Total } \\
\text { Precipitation } \\
\text { (in) }\end{array}$ & $\begin{array}{c}\text { Beer } \\
\text { Production } \\
\text { (1000 gal) }\end{array}$ & $\begin{array}{l}\text { Specialty } \\
\text { Breweries }\end{array}$ \\
\hline 1981 & 97262721.17 & $\$ 1.51$ & 42899.031 & 1.95 & 6048172.15 & 10 \\
\hline 1982 & 59579351.36 & $\$ 1.74$ & 41693.183 & 6.49 & 6024396.85 & 13 \\
\hline 1983 & 47915311.16 & $\$ 1.93$ & 37186.079 & 6.97 & 6084654.027 & 14 \\
\hline 1984 & 47918729.7 & $\$ 2.10$ & 30704.646 & 1.33 & 5983186.33 & 22 \\
\hline 1985 & 54778498.86 & $\$ 2.03$ & 28206.465 & 0.29 & 5992036.025 & 37 \\
\hline 1986 & 43568311.92 & $\$ 1.78$ & 25102.889 & 11.62 & 6090307.265 & 46 \\
\hline 1987 & 46299591.62 & $\$ 1.51$ & 28322.602 & 9.26 & 6057338.849 & 91 \\
\hline 1988 & 56622860.12 & $\$ 1.40$ & 33682.201 & 9.88 & 6115535.5 & 150 \\
\hline 1989 & 48677788.32 & $\$ 1.38$ & 34547.051 & 0.59 & 6171513.123 & 215 \\
\hline 1990 & 56488578.26 & $\$ 1.48$ & 35476.147 & 1.87 & 6313583.749 & 269 \\
\hline 1991 & 72155402.92 & $\$ 1.68$ & 39578.007 & 1.74 & 6268305.011 & 322 \\
\hline 1992 & 71661475.38 & $\$ 1.74$ & 42298.578 & 0.57 & 6265425.558 & 376 \\
\hline 1993 & 69798303.38 & $\$ 1.76$ & 43126.363 & 12.51 & 6268912.602 & 461 \\
\hline 1994 & 64213907.81 & $\$ 1.81$ & 42441.896 & 0.36 & 6262757.441 & 605 \\
\hline 1995 & 76258781.62 & $\$ 1.71$ & 43217.79 & 10.88 & 6172569.803 & 977 \\
\hline 1996 & 68323942.11 & $\$ 1.65$ & 44188.893 & 14.11 & 6234042.162 & 1277 \\
\hline 1997 & 65788654.5 & $\$ 1.60$ & 43333.927 & 4.65 & 6245771.31 & 1447 \\
\hline 1998 & 63474896.59 & $\$ 1.69$ & 36669.64 & 14.41 & 6155187.417 & 1625 \\
\hline 1999 & 63721242.28 & $\$ 1.69$ & 34188.756 & 16.87 & 6247620.5 & 1553 \\
\hline 2000 & 72109952.1 & $\$ 1.87$ & 36175.44 & 19.45 & 6141952.5 & 1469 \\
\hline 2001 & 56479630.57 & $\$ 1.91$ & 35913.514 & 3.24 & 6102327 & 1474 \\
\hline 2002 & 43510146.07 & $\$ 1.94$ & 29303.589 & 0.33 & 6196424.354 & 1552 \\
\hline 2003 & 47436678.99 & $\$ 1.90$ & 28668.542 & 5.21 & 6134450.072 & 1608 \\
\hline 2004 & 52083047.26 & $\$ 1.88$ & 27741.917 & 19.15 & 6139363.634 & 1613 \\
\hline 2005 & 53489775.19 & $\$ 1.94$ & 29543.276 & 11.17 & 6082382.165 & 1591 \\
\hline 2006 & 64450388.95 & $\$ 2.05$ & 29365.364 & 3.91 & 6106580.137 & 1721 \\
\hline 2007 & 52573188.77 & $\$ 2.99$ & 30912.21 & 0.90 & 6150907.863 & 1785 \\
\hline 2008 & 70244798.97 & $\$ 4.03$ & 40897.521 & 8.31 & 6122720.924 & 1876 \\
\hline 2009 & 62039302.82 & $\$ 3.57$ & 39726.267 & 8.07 & 6100662.729 & 1913 \\
\hline 2010 & 35297019.6 & $\$ 3.28$ & 31287.802 & 3.47 & 6018796.446 & 2111 \\
\hline 2011 & 52418065.38 & $\$ 3.14$ & 29787.905 & 4.71 & 5982922.16 & 2289 \\
\hline 2012 & 52249193.76 & $\$ 3.18$ & 31932.733 & 17.57 & 6057787.938 & 2731 \\
\hline
\end{tabular}

